\title{
Analysis and Modeling of Fatigue During Weight-Bearing Walking
}

\author{
Zhongqi Liu, Ruiming Zhang, and Qianxiang Zhou ${ }^{(\bowtie)}$ \\ Key Laboratory for Biomechanics and Mechanobiology of the Ministry \\ of Education, School of Biological Science and Medical Engineering, \\ Beihang University, Beijing 100191, China \\ \{liuzhongqi, zqxg\}@buaa. edu.cn
}

\begin{abstract}
The objective of this study was to discuss the mechanical characteristics and distributed regularity of shoulder, waist and back of the human body through the experiment of weight-bearing walking; to establish the dynamic fatigue model based on stress regularity to provide a reference for the task design of weight-bearing walking and the ergonomics simulation of backpack. Thirteen healthy people participated the experiment that was recruited by internet and they were all men. Every subject made a $21 \mathrm{~min}$ weight-bearing walking on the treadmill with the speed of $5 \mathrm{~km} / \mathrm{h}$ and a $15 \mathrm{~kg}$ load. The pressure data of their shoulder, back and waist was collected by pressure measuring system and the feeling of fatigue of the above three body parts of the subjects was asked every 3 min by using Borg scales. The results showed that the force of the subjects' left shoulder and right shoulder was different and the force was higher on one shoulder while it was lower on another shoulder. The stress regularities of waist and back were similar to the shoulders and it was higher on left side of some subjects while it was higher on right side of other subjects. Also the stress on waist and back was different. The stress on shoulder was much higher than it was on waist and back while the stress on back was the lowest. The impulse was calculated based on the stress data of three body parts. The model was established based that the impulse was as dependent variable and the feeling of subjects' fatigue was as independent variables. It showed a strong linear relationship between the pressure impulse of the three body parts and the feeling of subjects' fatigue. The subjects' fatigue could be well predicted during weight-bearing walking by using the linear model of impulse and subjective fatigue. So the conclusion of this study can be made that the stress on shoulder, back and waist is not asymmetric and it was great difference on the body three parts. The shoulder is not only the main bearing pressure part, but also the easiest part of fatigue. The fatigue can be well predicted during weight-bearing walking by the linear model that combine impulse and the feeling of subjects' fatigue.
\end{abstract}

Keywords: Weight-bearing walking $\cdot$ Fatigue $\cdot$ Mechanical characteristics $\cdot$ Impulse $\cdot$ Modeling 


\section{Introduction}

Weight-bearing Walking is closely related to people's lives, for example, March training for troops, workers' bear-loading, carrying the backpacks to school of students and so on. In the case of weight-bearing walking, the body will make the appropriate adjustments to achieve the body's balance and stability because of the pressure. Research showed that a series of injury problems will incur if people bear load too much or bear the weight for a long time [1-3]. Related medical research also proved that it is easy to cause foot blisters, stress fractures, lower limb joint pain, back muscle strain and the waist dish outstanding disease Under the condition of weight-bearing walking for a long time $[4,5]$. Research also found that weight bearing cause many adverse effects to children's growth and development [6, 7]. Therefore, to study on weight-bearing walking is significant to improve the design of backpack and reduce the body's fatigue.

In the relevant research field, studying the effect of weight-bearing walking on the human body took a large part, For example, the effects of weight - bearing walking on human gait and plantar pressure. However, weight-bearing walking is a behavior which caused human fatigue and if we carry out the research from the point of view of the composition and causes of fatigue, the results will be more practical significance, especially it provides a theoretical basis for the ergonomic design of weight-bearing. At present, there are four theories of great impact in this field: Levin's conservation model [8], QquF model [9], theory of Fatigue Motivation [10], and clue competition [11]. Levin's conservation model is a theoretical model of nursing work fatigue, it holds that fatigue is the behavior of the body to protect itself in short supply, but also a clue to the body's ability to imbalance. The QquF model is proposed by Angelique et al. The model is the relationship between external stimuli and fatigue. The theory suggests that when the attractiveness of external stimuli increases, people's feeling of fatigue will be reduced; when the external stimulus load increases, people's feeling of fatigue will be increase. Attractions of external stimuli mean that quality is negatively correlated with fatigue; Load of external stimuli means that quality and fatigue are positively correlated. The theory of fatigue motivation is a kind of theory about the relationship between motivation, fatigue and ability consumption, which was put forward by the American psychologist Maier RF based on previous experiments. And, the theory possesses a certain dialectical, cognitive color and a powerful explanation to phenomenon of life. Pennebaker proposed the clue competition, which is a theory of external stimulus and fatigue and holds that the result of clue competition is a curve relationship between external stimuli and fatigue. Four theories above fundamentally advance a core idea that fatigue is caused by multiple factors together. But at present, the mechanism of human fatigue in motion state has not been well explained, leading the limitations to describe the fatigue state. And it can't reflect the interrelationships between the various mechanisms.

In this paper, subjective and objective way was used together and the weight-bearing walking was as the research object. The Borg scale was used to quantify the fatigue caused by weight-bearing walking of young people. And then we established forecasting model of the fatigue of shoulder, waist and back by analyzing the characteristics of them. 


\section{Method}

\subsection{Participants}

Sixteen undergraduates participated in the experiment who 3 of them are preexperimental subjects and they were used to verify the feasibility of the experiment and improve the experimental design. Therefore, there were 13 participants in the formal experiment. All 16 participant were male who their age was 22-25 years, height was $170 \pm 4.1 \mathrm{~cm}$, weight was $72.5 \pm 4.2 \mathrm{~kg}$, and all of them were in good health. Subjects are required to avoid strenuous exercise before $24 \mathrm{~h}$ prior to the experiment and have a fully rest for fear that it would cause fatigue accumulation.

\subsection{Apparatus and Task}

The subjects were asked to walk on the treadmill carrying a $15 \mathrm{~kg}$ weight knapsack. The weight of $15 \mathrm{~kg}$ was a appropriate load based on pre-experiment and the load could avoid too light to lead subjects' fatigue and also could avoid too heavy causing body damage. The ground slope was zero degree. The subjects' walking speed $5 \mathrm{~km} / \mathrm{h}$ and the walking time was 21 min with zero degree of treadmill's slope. The walking speed of $5 \mathrm{~km} / \mathrm{h}$ referred to the speed requirements of troops March. Experiment time was set of 21 min to allow the subject to achieve a high degree of fatigue during the experiment without losing its physical limit. When the subjects asked to stop walking, in other words, the subjects couldn't continue walking with that walking speed, the experiment was over.

The force values of the shoulder, waist and back during walking were measured by a pressure measuring device. The arrangement of the pressure sensors was shown in Fig. 1. Every $3 \mathrm{~min}$, the Borg scale (see Table 1) was used to inquire the fatigue feeling of the subjects. And the subjects were asked to have an adaptive training before the experiment and wear safety rope during the experiment. When the subjects feel that it's hard to go on the experiment and appear unsteady gait, pale or chest tightness, etc., the experiment should stop immediately. Therefore, two security guards must be on the scene. One was in front of and the other was behind the platform. The experimental scene was shown as Fig. 2.

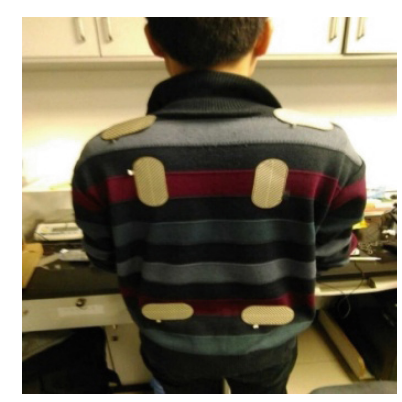

Fig. 1. The arrangement of force sensors 
Table 1. Comfort evaluation forms of shoulders, waist and backs

\begin{tabular}{|c|c|c|c|c|c|}
\hline \multirow[t]{2}{*}{ Body part } & \multicolumn{5}{|c|}{ Subjective feeling } \\
\hline & Best & Better & Normal & Ordinary & Poor \\
\hline Shoulders & $\begin{array}{l}\text { Feels a } \\
\text { constriction }\end{array}$ & A little pain & Painful & $\begin{array}{l}\text { A strong } \\
\text { pain }\end{array}$ & $\begin{array}{l}\text { A strong } \\
\text { pain }\end{array}$ \\
\hline Waist & $\begin{array}{l}\text { Slightly } \\
\text { oppressive }\end{array}$ & Oppressive & $\begin{array}{l}\text { Oppressive } \\
\text { obvious }\end{array}$ & $\begin{array}{l}\text { A little } \\
\text { pain }\end{array}$ & $\begin{array}{l}\text { A strong } \\
\text { pain }\end{array}$ \\
\hline Backs & $\begin{array}{l}\text { Slightly } \\
\text { oppressive }\end{array}$ & $\begin{array}{l}\text { Oppressive } \\
\text { obvious }\end{array}$ & A little pain & Painful & $\begin{array}{l}\text { A strong } \\
\text { pain }\end{array}$ \\
\hline Score & $0-2$ & $3-4$ & $5-6$ & $7-8$ & $9-10$ \\
\hline
\end{tabular}

Note: 0 means no fatigue. 10 means fatigue limit

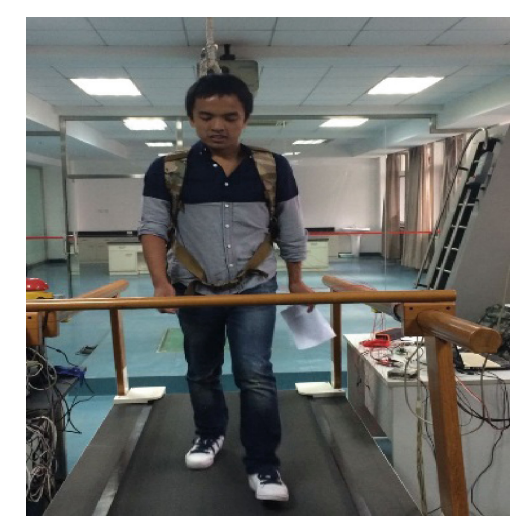

Fig. 2. Weight-bearing walking experiment

\subsection{Procedure}

When the subjects arrived at the experiment site, they performed the experiment according to the following process:

(1) The subjects were instructed to know the procedure and the Borg scale;

(2) The pressure sensor was fixed on every subject;

(3) Set the slope of treadmill to $0^{\circ}$ and launch it to start the experiment;

(4) Subjects were asked the degree of fatigue feeling with Borg scale every $3 \mathrm{~min}$ and the data was recorded by experimenters.

(5) The experiment was stopped After 21 min of walking of subjects.

\section{Results}

The average pressure on the left side of the shoulder of the 10 subjects was calculated every $3 \mathrm{~min}$, as shown in Table 2 . 
Table 2. The pressure of subjects' left shoulder (N)

\begin{tabular}{c|l|l|l|l|l|l|l|l|l|l}
\hline \multirow{2}{*}{$\begin{array}{c}\text { Time } \\
(\mathrm{min})\end{array}$} & \multicolumn{10}{l|}{ Subject number } \\
\cline { 2 - 13 } & 1 & 2 & 3 & 4 & 5 & 6 & 7 & 8 & 9 & 10 \\
\hline 0 & 0 & 0 & 0 & 0 & 0 & 0 & 0 & 0 & 0 & 0 \\
\hline 3 & 5.22 & 3.53 & 3.60 & 6.51 & 7.32 & 5.22 & 3.53 & 3.60 & 6.51 & 7.32 \\
\hline 6 & 5.10 & 3.62 & 4.81 & 6.63 & 7.65 & 5.10 & 3.62 & 4.81 & 6.63 & 7.65 \\
\hline 9 & 5.31 & 3.83 & 4.79 & 6.81 & 7.21 & 5.31 & 3.83 & 4.79 & 6.81 & 7.21 \\
\hline 12 & 4.98 & 3.45 & 3.49 & 7.68 & 7.30 & 4.98 & 3.45 & 3.49 & 7.68 & 7.30 \\
\hline 15 & 5.22 & 3.66 & 3.57 & 7.71 & 8.45 & 5.22 & 3.66 & 3.57 & 7.71 & 8.45 \\
\hline 18 & 5.33 & 3.58 & 4.70 & 6.64 & 7.44 & 5.33 & 3.58 & 4.70 & 6.64 & 7.44 \\
\hline 21 & 5.40 & 3.70 & 3.88 & 6.80 & 7.79 & 5.40 & 3.70 & 3.88 & 6.80 & 7.79 \\
\hline
\end{tabular}

Similarly, the average pressure of the right shoulder could be calculated and the result was shown in Table 3

Table 3. The pressure of subjects' right shoulder (N)

\begin{tabular}{c|l|l|l|l|l|l|l|l|l|l}
\hline \multirow{2}{*}{$\begin{array}{l}\text { Time } \\
(\mathrm{min})\end{array}$} & \multicolumn{6}{|l|}{ Subject number } \\
\cline { 2 - 13 } & 1 & 2 & 3 & 4 & 5 & 6 & 7 & 8 & 9 & 10 \\
\hline 0 & 0 & 0 & 0 & 0 & 0 & 0 & 0 & 0 & 0 & 0 \\
\hline 3 & 4.90 & 7.10 & 6.33 & 3.95 & 4.54 & 5.23 & 5.78 & 3.87 & 5.44 & 4.56 \\
\hline 6 & 4.10 & 5.99 & 7.10 & 4.68 & 3.90 & 4.67 & 6.10 & 4.78 & 5.89 & 5.10 \\
\hline 9 & 3.90 & 6.43 & 6.65 & 4.56 & 4.78 & 4.98 & 5.44 & 4.16 & 5.99 & 4.34 \\
\hline 12 & 4.20 & 5.67 & 6.22 & 4.19 & 3.99 & 3.67 & 5.87 & 4.46 & 6.21 & 4.89 \\
\hline 15 & 4.35 & 6.57 & 7.21 & 3.56 & 4.56 & 4.78 & 5.55 & 4.88 & 5.87 & 4.51 \\
\hline 18 & 3.76 & 5.40 & 6.65 & 4.21 & 3.32 & 4.57 & 5.10 & 4.31 & 6.22 & 4.76 \\
\hline 21 & 4.18 & 5.67 & 6.36 & 4.76 & 4.24 & 4.10 & 6.79 & 5.10 & 5.19 & 4.11 \\
\hline
\end{tabular}

Tables 2 and 3 showed that the force on subjects' left shoulder and right shoulder was inconsistent during the weight-bearing walking. But there was a common characteristic of all subjects that the force on one shoulder is smaller and the force of other shoulder is larger. It was also different of the pressure on shoulder of different subjects.

In the same way, the pressure of the waist and back of 10 subjects were calculated as shown in Tables 4, 5, 6, and 7 .

Seen from the data of Table 4, 5, 6, and 7, it could be found that the waist and back's force regularities are similar to shoulders'. Furthermore, there was no rule of the force on the same side (left or right) of different people. Specifically, some subjects had a larger stress on left shoulder and a smaller force on right shoulder while others are the opposite. Meanwhile, the pressure on the waist and back of each subject were also different.

Two characteristics could be found from the data of Tables 2, 3, 4, 5, 6, and 7. The first was that the pressure on waist is much smaller than that of shoulder while the force on the back is smaller than waist. The reason for this phenomenon was that the 
Table 4. The pressure of left side of subjects' waist (N)

\begin{tabular}{c|l|l|l|l|l|l|l|l|l|l}
\hline \multirow{2}{*}{$\begin{array}{c}\text { Time } \\
(\mathrm{min})\end{array}$} & \multicolumn{2}{|l|}{ Subject number } \\
\cline { 2 - 13 } & 1 & 2 & 3 & 4 & 5 & 6 & 7 & 8 & 9 & 10 \\
\hline 0 & 0 & 0 & 0 & 0 & 0 & 0 & 0 & 0 & 0 & 0 \\
\hline 3 & 2.31 & 1.01 & 0.76 & 2.10 & 1.11 & 1.67 & 2.57 & 1.03 & 2.43 & 0.89 \\
\hline 6 & 1.78 & 0.98 & 0.96 & 2.05 & 1.24 & 1.48 & 2.35 & 1.15 & 1.78 & 1.01 \\
\hline 9 & 2.65 & 1.32 & 0.87 & 1.98 & 1.35 & 1.79 & 1.98 & 1.08 & 2.10 & 0.91 \\
\hline 12 & 2.43 & 1.44 & 1.13 & 2.22 & 0.89 & 1.97 & 2.13 & 0.87 & 2.06 & 0.98 \\
\hline 15 & 1.67 & 0.76 & 0.88 & 1.76 & 1.01 & 1.55 & 2.11 & 0.96 & 1.98 & 0.96 \\
\hline 18 & 2.19 & 0.99 & 1.06 & 2.37 & 0.94 & 1.56 & 2.47 & 1.20 & 1.86 & 1.13 \\
\hline 21 & 2.57 & 1.21 & 1.01 & 2.08 & 0.91 & 1.68 & 2.15 & 0.79 & 2.01 & 1.02 \\
\hline
\end{tabular}

Table 5. The pressure of right side of subjects' waist (N)

\begin{tabular}{c|l|l|l|l|l|l|l|l|l|l}
\hline \multirow{2}{*}{$\begin{array}{c}\text { Time } \\
(\mathrm{min})\end{array}$} & \multicolumn{6}{|l}{ Subject number } \\
\cline { 2 - 13 } & 1 & 2 & 3 & 4 & 5 & 6 & 7 & 8 & 9 & 10 \\
\hline 0 & 0 & 0 & 0 & 0 & 0 & 0 & 0 & 0 & 0 & 0 \\
\hline 3 & 0.87 & 2.57 & 2.22 & 0.97 & 2.98 & 2.56 & 1.22 & 2.31 & 1.13 & 2.42 \\
\hline 6 & 0.79 & 2.78 & 2.01 & 0.85 & 2.78 & 2.41 & 1.26 & 2.01 & 1.21 & 2.57 \\
\hline 9 & 1.01 & 2.63 & 2.10 & 1.01 & 2.76 & 2.61 & 1.16 & 2.14 & 1.09 & 2.64 \\
\hline 12 & 1.11 & 2.43 & 1.98 & 0.97 & 2.57 & 2.72 & 1.07 & 2.12 & 1.06 & 2.31 \\
\hline 15 & 0.96 & 2.32 & 2.01 & 0.92 & 2.53 & 2.47 & 1.36 & 2.25 & 0.97 & 2.58 \\
\hline 18 & 0.89 & 2.53 & 2.15 & 0.88 & 2.87 & 2.58 & 1.18 & 2.09 & 1.15 & 2.68 \\
\hline 21 & 0.93 & 2.68 & 2.12 & 1.03 & 2.82 & 2.60 & 1.25 & 2.18 & 1.05 & 2.41 \\
\hline
\end{tabular}

Table 6. The pressure of left side of subjects' back (N)

\begin{tabular}{c|l|l|l|l|l|l|l|l|l|l}
\hline \multirow{2}{*}{$\begin{array}{c}\text { Time } \\
(\mathrm{min})\end{array}$} & \multicolumn{9}{|l|}{ Subject number } \\
\cline { 2 - 13 } & 1 & 2 & 3 & 4 & 5 & 6 & 7 & 8 & 9 & 10 \\
\hline 0 & 0 & 0 & 0 & 0 & 0 & 0 & 0 & 0 & 0 & 0 \\
\hline 3 & 0.57 & 0.89 & 1.01 & 0.51 & 0.78 & 1.12 & 0.58 & 1.13 & 0.72 & 1.02 \\
\hline 6 & 0.68 & 0.78 & 0.98 & 0.52 & 0.84 & 1.05 & 0.76 & 1.21 & 0.64 & 0.88 \\
\hline 9 & 0.62 & 0.84 & 0.89 & 0.64 & 0.73 & 0.97 & 0.67 & 1.07 & 0.58 & 0.98 \\
\hline 12 & 0.53 & 0.83 & 1.10 & 0.63 & 0.72 & 1.08 & 0.52 & 1.05 & 0.76 & 0.97 \\
\hline 15 & 0.59 & 0.75 & 1.03 & 0.52 & 0.81 & 1.03 & 0.64 & 1.01 & 0.66 & 1.10 \\
\hline 18 & 0.63 & 0.78 & 0.92 & 0.56 & 0.83 & 0.89 & 0.53 & 1.14 & 0.69 & 1.03 \\
\hline 21 & 0.61 & 0.87 & 0.87 & 0.53 & 0.76 & 0.97 & 0.56 & 1.05 & 0.59 & 1.07 \\
\hline
\end{tabular}

shoulder is the main load-bearing area during weight-bearing walking. The pressure sensor on the shoulder was easier to fix than the waist and back and was always close to the surface of clothing during the experiment. The force on the waist and back was 
Table 7. The pressure of right side of subjects' back $(\mathrm{N})$

\begin{tabular}{c|l|l|l|l|l|l|l|l|l|l}
\hline \multirow{2}{*}{$\begin{array}{c}\text { Time } \\
(\mathrm{min})\end{array}$} & \multicolumn{2}{l|}{ Subject number } \\
\cline { 2 - 14 } & 1 & 2 & 3 & 4 & 5 & 6 & 7 & 8 & 9 & 10 \\
\hline 0 & 0 & 0 & 0 & 0 & 0 & 0 & 0 & 0 & 0 & 0 \\
\hline 3 & 0.97 & 1.03 & 0.58 & 1.12 & 1.21 & 0.76 & 0.89 & 0.78 & 1.14 & 0.54 \\
\hline 6 & 1.01 & 1.06 & 0.67 & 1.04 & 1.16 & 0.82 & 0.79 & 0.86 & 1.04 & 0.62 \\
\hline 9 & 0.87 & 0.96 & 0.62 & 1.16 & 1.17 & 0.83 & 0.85 & 0.63 & 0.96 & 0.58 \\
\hline 12 & 0.92 & 0.91 & 0.70 & 1.01 & 1.08 & 0.68 & 0.92 & 0.84 & 1.03 & 0.52 \\
\hline 15 & 0.95 & 0.85 & 0.72 & 1.09 & 1.14 & 0.72 & 0.86 & 0.75 & 1.06 & 0.68 \\
\hline 18 & 1.03 & 1.12 & 0.59 & 0.95 & 1.01 & 0.70 & 0.88 & 0.82 & 1.14 & 0.53 \\
\hline 21 & 1.05 & 1.04 & 0.68 & 1.07 & 1.04 & 0.83 & 0.83 & 0.77 & 1.13 & 0.51 \\
\hline
\end{tabular}

difficult to measure by sensor. On the one hand, during the experiment, limited by sensors' area, subjects' slightly shaking caused that the pressure sensor deviates from its original position or slack and it couldn't be completely contacted with the body. The subject's subjective fatigue score of the shoulder was higher than back and waist. That is to say, the main cause of fatigue was that the shoulders suffer sustained high-intensity pressure, which leading to the whole body fatigue. This proved that the shoulder is the most vulnerable part in the weight-bearing walking, which is consistent with the relevant research results. The second characteristic was that there is no consistency of the stress on the experimenters' shoulder, waist, back. In the other words, when the stress on shoulder of one subject was higher than anther subject, it couldn't make sure that the magnitude of stress on waist of one person is larger than another person. The reason was that each human is an independent individual and there is no exactly same man. Meanwhile, stress-bearing parts were not only the shoulder, waist and back.

\section{The Model of Fatigue Evaluation}

Impulse of calculus algorithm as follows:

$$
I=\int_{t 1}^{t 2} f d t
$$

Where "I" is the impulse of the force, "t1" and "t2" are the time, and "f" is the force.

When the value of the force $f$ was the average, the impulse of the force I was $\mathrm{I}=\mathrm{f} \times\left(\mathrm{t}_{2}-\mathrm{t}_{1}\right)$. Taking into account the degree of fatigue would increase with the increase of time, the product of pressure of shoulder, waist, back and time could be calculated every $3 \mathrm{~min}$. The product result could be regarded as a factor in the fatigue evaluation model. The Tables $8,9,10,11,12$, and 13 showed the product which is the result of multiply time by the force of every part on human. 
Table 8. The impulse of larger force side of subjects' shoulder (Ns)

\begin{tabular}{c|r|r|r|r|l|l|l|l|r|r}
\hline \multirow{2}{*}{$\begin{array}{c}\text { Time } \\
(\mathrm{min})\end{array}$} & \multicolumn{2}{|l|}{ Subject number } \\
\cline { 2 - 14 } & 1 & 2 & 3 & 4 & 5 & 6 & 7 & 8 & 9 & 10 \\
\hline 0 & 0 & 0 & 0 & 0 & 0 & 0 & 0 & 0 & 0 & 0 \\
\hline 3 & 939 & 1278 & 1139 & 1171 & 1317 & 1242 & 1040 & 1062 & 1497 & 963 \\
\hline 6 & 1857 & 2356 & 2417 & 2365 & 2694 & 2359 & 2138 & 2196 & 2775 & 2061 \\
\hline 9 & 2813 & 3513 & 3614 & 3591 & 3992 & 3675 & 3117 & 3241 & 4120 & 3180 \\
\hline 12 & 3709 & 4534 & 4734 & 4973 & 5306 & 4915 & 4174 & 4318 & 5466 & 4181 \\
\hline 15 & 4649 & 5716 & 6031 & 6361 & 6827 & 6273 & 5173 & 5416 & 6942 & 5338 \\
\hline 18 & 5608 & 6688 & 7228 & 7556 & 8166 & 7470 & 6091 & 6568 & 8262 & 6397 \\
\hline 21 & 6580 & 7709 & 8373 & 8780 & 9568 & 8587 & 7313 & 7743 & 9682 & 7513 \\
\hline
\end{tabular}

Table 9. The impulse of smaller force side of subjects' shoulder (Ns)

\begin{tabular}{c|r|r|r|r|r|r|r|r|l|l}
\hline \multirow{2}{*}{$\begin{array}{c}\text { Time } \\
(\mathrm{min})\end{array}$} & \multicolumn{2}{|l|}{ Subject number } \\
\cline { 2 - 13 } & 1 & 2 & 3 & 4 & 5 & 6 & 7 & 8 & 9 & 10 \\
\hline 0 & 0 & 0 & 0 & 0 & 0 & 0 & 0 & 0 & 0 & 0 \\
\hline 3 & 882 & 1278 & 648 & 711 & 817 & 941 & 758 & 697 & 979 & 821 \\
\hline 6 & 1620 & 2356 & 1514 & 1553 & 1519 & 1782 & 1571 & 1557 & 2039 & 1739 \\
\hline 9 & 2322 & 3514 & 2376 & 2374 & 2380 & 2678 & 2349 & 2306 & 3118 & 2520 \\
\hline 12 & 3078 & 4534 & 3004 & 3128 & 3098 & 3339 & 2950 & 3109 & 4235 & 3400 \\
\hline 15 & 3861 & 5717 & 3647 & 3769 & 3919 & 4199 & 3730 & 3987 & 5292 & 4212 \\
\hline 18 & 4538 & 6689 & 4493 & 4527 & 4516 & 5022 & 4433 & 4763 & 6412 & 5069 \\
\hline 21 & 5290 & 7709 & 5191 & 5384 & 5279 & 5760 & 5211 & 5681 & 7346 & 5809 \\
\hline
\end{tabular}

Table 10. The impulse of larger force side of subjects' waist (Ns)

\begin{tabular}{c|r|r|r|r|r|r|r|r|r|r}
\hline $\begin{array}{l}\text { Time } \\
(\mathrm{min})\end{array}$ & \multicolumn{2}{|l|}{ Subject number } \\
\cline { 2 - 14 } & 1 & 2 & 3 & 4 & 5 & 6 & 7 & 8 & 9 & 10 \\
\hline 0 & 0 & 0 & 0 & 0 & 0 & 0 & 0 & 0 & 0 & 0 \\
\hline 3 & 416 & 463 & 400 & 378 & 536 & 461 & 463 & 416 & 437 & 436 \\
\hline 6 & 736 & 963 & 761 & 747 & 1037 & 895 & 963 & 778 & 758 & 898 \\
\hline 9 & 1213 & 1436 & 1139 & 1103 & 1534 & 1364 & 1436 & 1163 & 1136 & 1373 \\
\hline 12 & 1651 & 1874 & 1496 & 1503 & 1996 & 1854 & 1874 & 1544 & 1507 & 1789 \\
\hline 15 & 1951 & 2291 & 1858 & 1820 & 2452 & 2299 & 2291 & 1949 & 1863 & 2254 \\
\hline 18 & 2345 & 2747 & 2245 & 2246 & 2968 & 2763 & 2747 & 2326 & 2198 & 2736 \\
\hline 21 & 2808 & 3229 & 2626 & 2621 & 3476 & 3231 & 3229 & 2718 & 2560 & 3170 \\
\hline
\end{tabular}


Table 11. The impulse of smaller force side of subjects' waist (Ns)

\begin{tabular}{|c|c|c|c|c|c|c|c|c|c|c|}
\hline \multirow{2}{*}{$\begin{array}{l}\text { Time } \\
\text { (min) }\end{array}$} & \multicolumn{10}{|c|}{ Subject number } \\
\hline & 1 & 2 & 3 & 4 & 5 & 6 & 7 & 8 & 9 & 10 \\
\hline 0 & 0 & 0 & 0 & 0 & 0 & 0 & 0 & 0 & 0 & 0 \\
\hline 3 & 157 & 182 & 137 & 175 & 200 & 301 & 220 & 185 & 203 & 160 \\
\hline 6 & 299 & 358 & 310 & 328 & 423 & 567 & 446 & 392 & 421 & 342 \\
\hline 9 & 481 & 596 & 466 & 509 & 666 & 889 & 655 & 587 & 617 & 682 \\
\hline 12 & 680 & 855 & 670 & 684 & 826 & 1244 & 848 & 743 & 808 & 859 \\
\hline 15 & 853 & 992 & 828 & 850 & 1008 & 1523 & 1093 & 916 & 983 & 1031 \\
\hline 18 & 1013 & 1170 & 1019 & 1008 & 1177 & 1804 & 1305 & 1132 & 1190 & 1235 \\
\hline 21 & 1181 & 1388 & 1201 & 1193 & 1341 & 2106 & 1530 & 1274 & 1379 & 1418 \\
\hline
\end{tabular}

Table 12. The impulse of larger force side of subjects' back (Ns)

\begin{tabular}{c|r|r|r|r|r|r|r|r|r|r}
\hline \multirow{2}{*}{$\begin{array}{c}\text { Time } \\
(\mathrm{min})\end{array}$} & \multicolumn{6}{|l|}{ Subject number } \\
\cline { 2 - 14 } & 1 & 2 & 3 & 4 & 5 & 6 & 7 & 8 & 9 & 10 \\
\hline 0 & 0 & 0 & 0 & 0 & 0 & 0 & 0 & 0 & 0 & 0 \\
\hline 3 & 175 & 185 & 182 & 202 & 202 & 202 & 160 & 203 & 205 & 184 \\
\hline 6 & 356 & 376 & 358 & 389 & 410 & 391 & 302 & 421 & 392 & 342 \\
\hline 9 & 513 & 549 & 518 & 598 & 621 & 565 & 455 & 614 & 565 & 518 \\
\hline 12 & 679 & 713 & 716 & 779 & 815 & 760 & 621 & 803 & 751 & 693 \\
\hline 15 & 850 & 866 & 902 & 976 & 1021 & 945 & 776 & 985 & 941 & 891 \\
\hline 18 & 1035 & 1067 & 1067 & 1147 & 1202 & 1105 & 934 & 1190 & 1147 & 1076 \\
\hline 21 & 1224 & 1255 & 1224 & 1339 & 1390 & 1280 & 1084 & 1379 & 1350 & 1269 \\
\hline
\end{tabular}

Table 13. The impulse of smaller force side of subjects' back (Ns)

\begin{tabular}{l|r|r|l|r|l|l|l|l|l|r}
\hline $\begin{array}{l}\text { Time } \\
(\mathrm{min})\end{array}$ & \multicolumn{2}{|l|}{ Subject number } \\
\cline { 2 - 15 } & 1 & 2 & 3 & 4 & 5 & 6 & 7 & 8 & 9 & 10 \\
\hline 0 & 0 & 0 & 0 & 0 & 0 & 0 & 0 & 0 & 0 & 0 \\
\hline 3 & 103 & 160 & 104 & 92 & 140 & 137 & 104 & 140 & 130 & 97 \\
\hline 6 & 225 & 301 & 225 & 185 & 292 & 284 & 241 & 295 & 245 & 209 \\
\hline 9 & 337 & 452 & 337 & 301 & 423 & 434 & 362 & 409 & 349 & 313 \\
\hline 12 & 432 & 601 & 463 & 414 & 553 & 556 & 455 & 560 & 486 & 407 \\
\hline 15 & 538 & 736 & 592 & 508 & 698 & 686 & 571 & 695 & 605 & 529 \\
\hline 18 & 652 & 877 & 698 & 608 & 848 & 812 & 666 & 842 & 729 & 625 \\
\hline 21 & 761 & 1033 & 821 & 704 & 985 & 961 & 767 & 981 & 835 & 716 \\
\hline
\end{tabular}

The Borg score and impulses of the bigger force value and the smaller force value on each part of human were plotted. As shown in Figs. 3, 4, 5, 6, 7, and 8. 


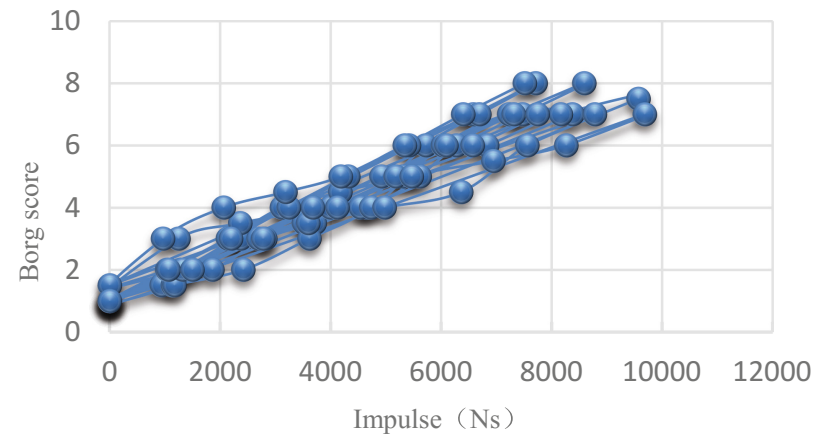

Fig. 3. The scatter diagram of Borg score and impulse of larger force side of shoulder

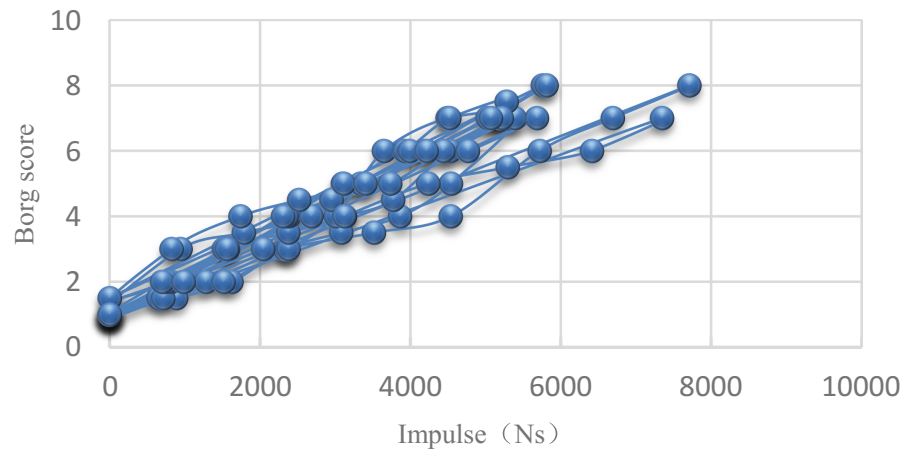

Fig. 4. The scatter diagram of Borg score and impulse of smaller force side of shoulder

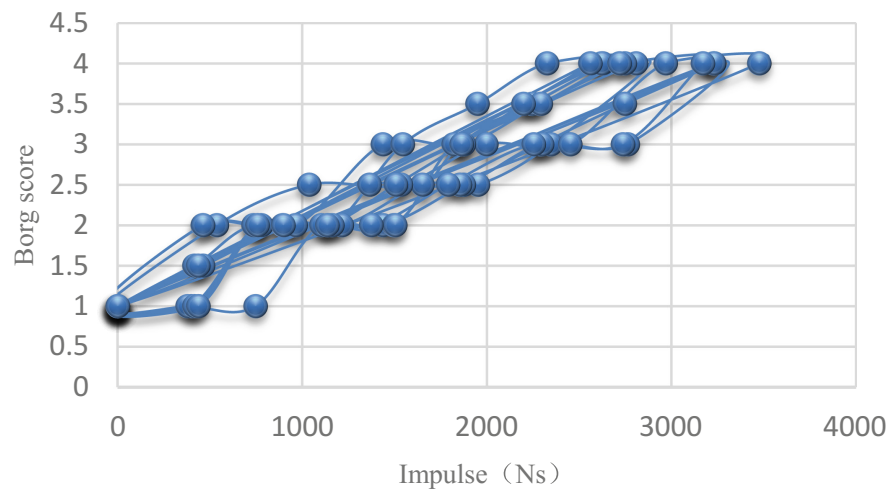

Fig. 5. The scatter diagram of Borg score and impulse of larger force side of waist 


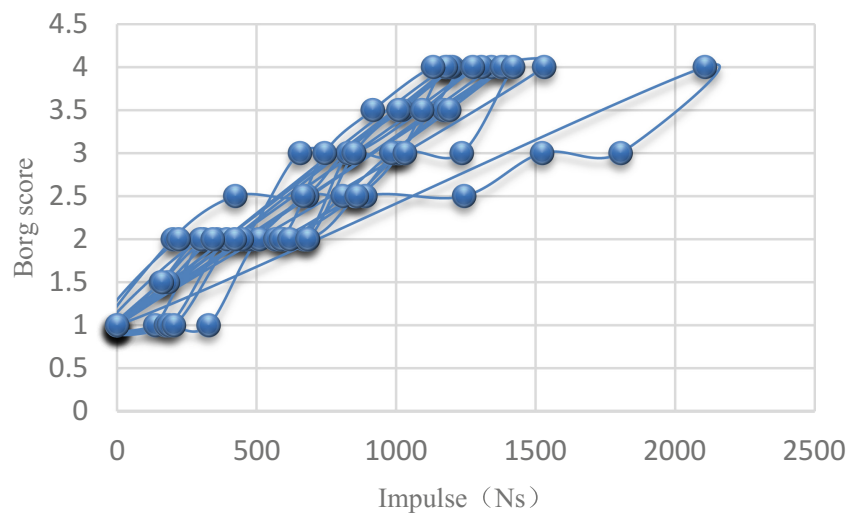

Fig. 6. The scatter diagram of Borg score and impulse of smaller force side of waist

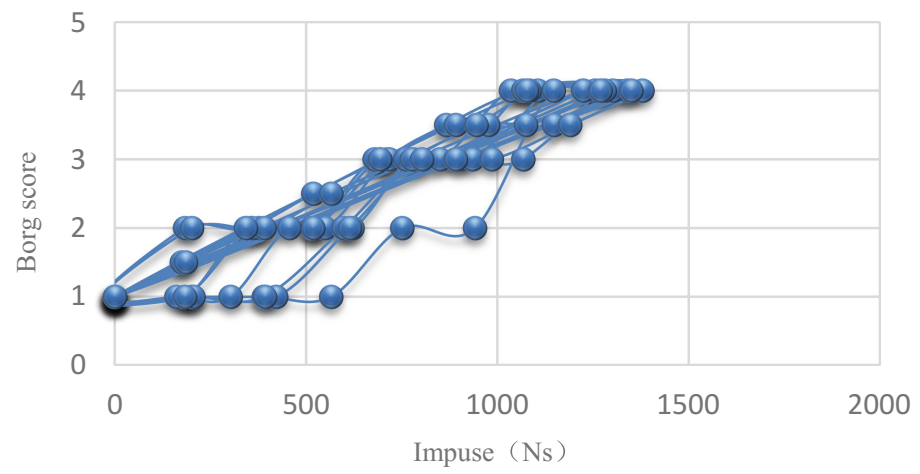

Fig. 7. The scatter diagram of Borg score and impulse of larger force side of waist

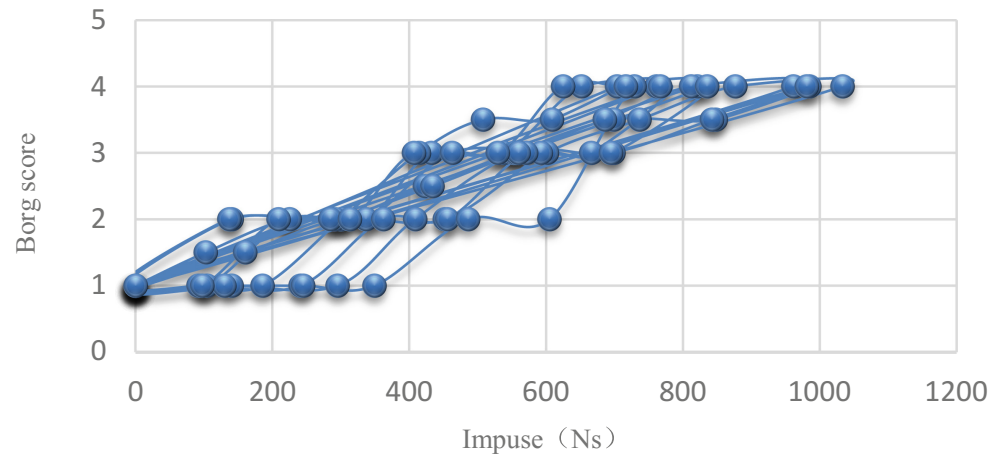

Fig. 8. The scatter diagram of Borg score and impulse of smaller force side of back 
The above graphics indicate that the pressure impulse has a strong linear relationship with the subjective feeling of fatigue. Therefore, single linear regression models of fatigue evaluation of shoulder, waist and back were established that the independent variable is the pressure impulse I of the shoulder, waist and back, and the dependent variable is the subjective feeling of fatigue B, as shown in Eqs. 2-7.

The fatigue model of the larger force side of shoulder:

$$
\mathrm{B}=1.0 \times 10^{-3} I+1.223 \quad \mathrm{R}=0.958
$$

The fatigue model of the smaller force side of shoulder:

$$
\mathrm{B}=1.0 \times 10^{-3} I+1.271 \quad \mathrm{R}=0.944
$$

The fatigue model of the larger force side of waist:

$$
\mathrm{B}=1.0 \times 10^{-3} I+1.029 \quad \mathrm{R}=0.947
$$

The fatigue model of the smaller force side of waist:

$$
\mathrm{B}=2.0 \times 10^{-3} I+1.152 \quad \mathrm{R}=0.907
$$

The fatigue model of the larger force side of back:

$$
\mathrm{B}=2.0 \times 10^{-3} I+0.859 \quad \mathrm{R}=0.934
$$

The fatigue model of the smaller force side of back:

$$
\mathrm{B}=4.0 \times 10^{-3} I+0.907 \quad \mathrm{R}=0.925
$$

The fatigue value of shoulder, waist and back of the remaining three persons were calculated with the above model. The value was compared to the subject feeling of fatigue during the experiment of the corresponding body part. The error could be used to verify the model's precision or reliability. The fatigue value of model and the value of experiment were shown in Tables 14, 15, and 16. It could be seen that the error of each model is less than \pm 1.3 , which satisfies the accuracy requirement and prove the model's precision.

Considered the definition of impulse in physics, the impulse of shoulder, waist and back were chose as the fatigue evaluation index of weight-bearing walking. Impulse is the cumulative effect of force on time, which is consistent with the increase in body fatigue over time. At the same time, the independent variable of the model combines the relation of force and time, which fatigue is result from a complex, multi-factor working together. The fatigue evaluation model's high linearity showed that the model is feasible and it proved a theoretical fact that fatigue is caused by a complicated and multi - factor common. 
Table 14. The verification result of the first subject

\begin{tabular}{l|l|l|l|l|l|l|l|l|l}
\hline \multirow{2}{*}{$\begin{array}{l}\text { Time } \\
(\mathrm{min})\end{array}$} & \multicolumn{2}{|l|}{ Experiment value } & \multicolumn{2}{l}{ Model value } \\
\cline { 2 - 10 } & Shoulder & Waist & Back & $\begin{array}{l}\text { Shoulder } \\
\text { (larger) }\end{array}$ & $\begin{array}{l}\text { Shoulder } \\
\text { (smaller) }\end{array}$ & $\begin{array}{l}\text { Waist } \\
\text { (larger) }\end{array}$ & $\begin{array}{l}\text { Waist } \\
\text { (smaller) }\end{array}$ & $\begin{array}{l}\text { Back } \\
\text { (larger) }\end{array}$ & $\begin{array}{l}\text { Back } \\
\text { (smaller) }\end{array}$ \\
\hline 0 & 1.0 & 1.0 & 1.0 & 1.1 & 1.1 & 1.0 & 1.0 & 0.8 & 0.8 \\
\hline 3 & 2.0 & 1.0 & 1.0 & 2.0 & 2.1 & 1.4 & 1.4 & 1.3 & 1.3 \\
\hline 6 & 3.0 & 1.5 & 1.5 & 2.8 & 2.9 & 1.8 & 1.8 & 1.8 & 1.8 \\
\hline 9 & 3.5 & 2.0 & 1.5 & 3.6 & 3.7 & 2.2 & 2.3 & 2.2 & 2.2 \\
\hline 12 & 4.0 & 2.5 & 2.0 & 4.4 & 4.6 & 2.7 & 2.8 & 2.7 & 2.5 \\
\hline 15 & 5.0 & 3.0 & 2.5 & 5.3 & 5.4 & 3.0 & 3.4 & 3.1 & 3.1 \\
\hline 18 & 7.0 & 3.5 & 3.0 & 6.0 & 6.3 & 3.4 & 3.7 & 3.6 & 3.5 \\
\hline 21 & 7.0 & 4.0 & 4.0 & 7.0 & 7.2 & 3.9 & 4.2 & 4.0 & 4.0 \\
\hline
\end{tabular}

Table 15. The verification result of the second subject

\begin{tabular}{l|l|l|l|l|l|l|l|l|l}
\hline \multirow{2}{*}{$\begin{array}{l}\text { Time } \\
(\mathrm{min})\end{array}$} & \multicolumn{2}{|l|}{ Experiment value } & \multicolumn{2}{l}{ Model value } \\
\cline { 2 - 10 } & Shoulder & Waist & Back & $\begin{array}{l}\text { Shoulder } \\
\text { (larger) }\end{array}$ & $\begin{array}{l}\text { Shoulder } \\
\text { (smaller) }\end{array}$ & $\begin{array}{l}\text { Waist } \\
\text { (larger) }\end{array}$ & $\begin{array}{l}\text { Waist } \\
\text { (smaller) }\end{array}$ & $\begin{array}{l}\text { Back } \\
\text { (larger) }\end{array}$ & $\begin{array}{l}\text { Back } \\
\text { (smaller) }\end{array}$ \\
\hline 0 & 1.0 & 1.0 & 1.0 & 1.1 & 1.1 & 1.0 & 1.0 & 0.8 & 0.8 \\
\hline 3 & 2.0 & 1.5 & 1.5 & 2.1 & 2.0 & 1.3 & 1.3 & 1.3 & 1.2 \\
\hline 6 & 4.0 & 2.0 & 1.5 & 3.3 & 3.0 & 1.7 & 1.7 & 1.6 & 1.7 \\
\hline 9 & 4.5 & 2.0 & 2.0 & 4.1 & 3.9 & 2.0 & 2.1 & 2.1 & 2.1 \\
\hline 12 & 5.0 & 2.5 & 2.5 & 5.0 & 4.7 & 2.3 & 2.5 & 2.6 & 2.5 \\
\hline 15 & 5.5 & 3.0 & 3.0 & 6.0 & 5.4 & 2.6 & 2.7 & 3.0 & 3.0 \\
\hline 18 & 6.0 & 3.5 & 3.0 & 7.3 & 6.0 & 2.9 & 3.1 & 3.3 & 3.4 \\
\hline 21 & 7.0 & 4.0 & 4.0 & 8.2 & 6.9 & 3.3 & 3.7 & 3.9 & 3.9 \\
\hline
\end{tabular}

Table 16. The verification result of the third subject

\begin{tabular}{l|l|l|l|l|l|l|l|l|l}
\hline \multirow{2}{*}{$\begin{array}{l}\text { Time } \\
(\mathrm{min})\end{array}$} & \multicolumn{2}{|l|}{ Experiment value } & \multicolumn{2}{l}{ Model value } \\
\cline { 2 - 10 } & Shoulder & Waist & Back & $\begin{array}{l}\text { Shoulder } \\
\text { (larger) }\end{array}$ & $\begin{array}{l}\text { Shoulder } \\
\text { (smaller) }\end{array}$ & $\begin{array}{l}\text { Waist } \\
\text { (larger) }\end{array}$ & $\begin{array}{l}\text { Waist } \\
\text { (smaller) }\end{array}$ & $\begin{array}{l}\text { Back } \\
\text { (larger) }\end{array}$ & $\begin{array}{l}\text { Back } \\
\text { (smaller) }\end{array}$ \\
\hline 0 & 1.0 & 1.0 & 1.0 & 1.1 & 1.1 & 1.0 & 1.0 & 0.8 & 0.8 \\
\hline 3 & 2.0 & 2.0 & 2.0 & 2.0 & 2.2 & 1.5 & 1.3 & 1.1 & 1.4 \\
\hline 6 & 3.0 & 2.0 & 2.5 & 3.1 & 3.0 & 1.8 & 1.7 & 1.5 & 1.7 \\
\hline 9 & 4.0 & 2.5 & 2.5 & 4.0 & 4.2 & 2.3 & 2.0 & 1.8 & 2.3 \\
\hline 12 & 5.0 & 2.5 & 3.0 & 4.9 & 5.3 & 2.7 & 2.3 & 2.2 & 2.8 \\
\hline 15 & 6.0 & 3.0 & 3.5 & 5.7 & 6.1 & 3.1 & 2.9 & 2.5 & 3.1 \\
\hline 18 & 6.5 & 4.0 & 3.5 & 6.6 & 7.3 & 3.5 & 3.1 & 2.9 & 3.6 \\
\hline 21 & 8.0 & 4.0 & 4.0 & 7.6 & 8.3 & 4.1 & 3.5 & 3.2 & 4.1 \\
\hline
\end{tabular}




\section{Conclusion}

It is very important to carry out load-bearing walking fatigue research, to evaluate the damage caused by different load to human body, to scientifically design load task and to improve the design of backpack. So the specific conclusions of this study are as follows:

(1) The shoulder is the main area of bearing pressure and also is the most easily fatigue during the process of weight-bearing walking.

(2) During the weight-bearing walking, the force of the different side of the human's same parts is different and the difference is significant.

(3) The fatigue evaluation model combines the subjective feeling of fatigue and the objective index of the impulse of shoulder, waist and back and it avoid the simplification of fatigue evaluation model of current study, so the model of this study is a improvement.

Acknowledgement. This research was funded by Electronic information equipment system research of Key laboratory of basic research projects of national defense technology (DXZT-JC-ZZ-2015-016).

\section{References}

1. Wang, J., Xu, X., Liu, Y.: Dynamic foot pressure measurements and its application to clinical or thopaedics. J. Appl. Biomech. 12(3), 170-175 (1997)

2. Birrell, S.A., Haslam, R.A.: The effect of load distribution within military load carriage systems on the kinetics of human gait. Appl. Ergon. 41(4), 585-590 (2010)

3. Rugelj, D., Sevek, F.: The effect of load mass and its placement on postural sway. Appl. Ergon. 42(6), 860-866 (2011)

4. Wei, J., Song, L.: The development of biomechanics studies on human's load carriage gait. J. Jilin Normal Univ. (Nat. Sci. Edn.) 4, 122-124 (2010)

5. Yuan, G., Zhang, J., Zhang, M., et al.: The measurement system for dynamic foot pressure and its clinical application 18(1), 22-25

6. Geng, H.: Foot pressure features of single-shoulder and double-shoulder schoolbag weight walk of children. J. Clin. Rehabil. Tissue Eng. Res. 15(33), 6267-6270 (2011)

7. $\mathrm{Wu}, \mathrm{T}$., Gong, T., Zhou, Y., Zhang, C.: Research on plantar pressure and gait for children aged from 6 to 10 in loading condition. China Leather 44(13), 24-27 (2015)

8. Gribble, P.A., Hertel, J., Denegar, C.R., Buckley, W.E.: The effects of fatigue and chronic ankle instability on dynamic postural control. J. Athl. Train. 39, 321-329 (2004)

9. De Rijk, A.E., Schreurs, K.M.G., Bensing, J.M.: What is behind "I'm so tired?" Fatigue experiences and their relations to the quality and quantity of external stimulation. Psychosom. Res. 47(6), 509-523 (1999)

10. Jing, G., Lang, X., Yao, Z.: The method and countermeasure of fatigue investigate. Jpn. Med. Introd. 24(12), 566-568 (2003)

11. Xue, X., Wang, T., Zhao, Y., et al.: Connotation of "fatigue" symptom and thought of its quantization evaluation. China J. Tradit. Chin. Med. Pharm. 21(5), 267-269 (2006) 